\title{
Müller-Lyer illusion and the structure-strategy dichotomy
}

\author{
GARY M. BROSVIC, MARGARET FARRELLY, JUDITH M. RISSER, \\ JENNIFER SHANDER, JODY CLAYTON, ELIZABETH SYPEK, and LOREEN KAFER \\ Rider College, Lawrenceville, New Jersey \\ and \\ ROBERTA E. DIHOFF \\ Glassboro State College, Glassboro, New Jersey
}

(Michael Epstein, Sponsor)

\begin{abstract}
The relative contributions of structural and strategic factors involved in the Müller-Lyer illusion were examined as a function of training procedure. Estimates of structural and strategic factors were procedure specific, and greater correction of inaccurate strategic factors was observed for subjects trained with feedback than for those trained with visual-inspection or control procedures. No additive effects of combining feedback with visual inspection were observed.
\end{abstract}

The structure-strategy concept has been used to dichotomize results of studies on illusions into structure, including distortions attributable to the neural properties of the visual system, and strategy, including routine problemsolving strategies (Girgus, Coren, Durant, \& Porac, 1975). In studies of the Müller-Lyer (ML) illusion, subjects typically visually scan the adjustable and fixed lines of the stimulus figure during intertrial intervals (ITIs) and then adjust the two lines to equality.

Decreases in magnitude of illusion between the first and final inspections define illusion decrement and support a hypothesis by Girgus et al. (1975) that first inspections contain components of both factors, whereas final inspections estimate the correction of inaccurate cognitive strategies, with residual error estimating the unalterable contributions of structural factors. Estimates of strategic factors determined via visual inspection for the ML illusion range from $40 \%$ to $60 \%$, with longer and multiple exposure sessions resulting in somewhat larger estimates (Girgus et al., 1975). Estimates of strategic factors for the horizontal-vertical (HV) illusion range from $43 \%$ for training with visual inspection to $90 \%$ for training with feedback (Brosvic \& Cohen, 1988; Brosvic, Rowe-Boyer, \& Dihoff, 1991; Rowe-Boyer \& Brosvic, 1990).

The HV illusion has been classified as being more cognitive in etiology than the ML illusion (Coren, Girgus, Erlichman, \& Hakstian, 1976), and it is thus of considerable theoretical interest to examine whether magnitude for illusion on the ML illusion is reduced by training with

Preliminary results of this study were presented at the 1991 Annual Meeting of the New Jersey Psychological Association. Correspondence should be addressed to G. M. Brosvic, Biopsychology Laboratory, Department of Psychology, Rider College, 2083 Lawrenceville Road, Lawrenceville, NJ 08648-3099. feedback to a greater degree than training with visual inspection. In the present study, estimates of structural and strategic factors involved in the ML illusion were determined with training by feedback, visual inspection, the combination of feedback and visual inspection, or control procedures. It was predicted that estimates of strategic factors would differ between the feedback and the visualinspection groups, the feedback and the combinedprocedures groups, and the training groups and the controls.

\section{METHOD}

\section{Subjects}

Sixty-four women and 16 men (aged 16-39 years) served as subjects and were drawn from a human-subjects pool. Each subject reported normal or corrected-to-normal 20/20 visual acuity, and 16 women and 4 men were randomly assigned to each group described below.

\section{Stimuli}

The ML illusion apparatus produced by Lafayette Instruments (Lafayette, Indiana) was used. The fixed and adjustable lines were 229 and $381 \mathrm{~mm}$ in length, respectively, and the length of the wingshaft arrows was $25.4 \mathrm{~mm}$.

\section{Procedure}

The initial inspection and adjustment was counted as Minute 0 , with additional adjustments made after 60 -sec ITIs. Eleven adjustments were made, and prior to each, the experimenter relocated the adjustable line inward (100\% too short) or outward (100\% too long), with this order counterbalanced and half of the subjects beginning with the line relocated inward.

In the feedback group, the subjects were told the amount (percent) and direction (under- or overestimation) of error after each adjustment. In the visual-inspection group, both lines were set to equality and visually scanned for $60 \mathrm{sec}$. At the end of the ITI, the adjustable line was relocated and the subjects then set the lines to perceived equality. In the combined-procedures group, the lines were set to equality and visually scanned for $60 \mathrm{sec}$. At the end of the ITI, the adjustable line was relocated, with the subjects then setting the lines to perceived equality and being told the amount and direction of error. Control group subjects 


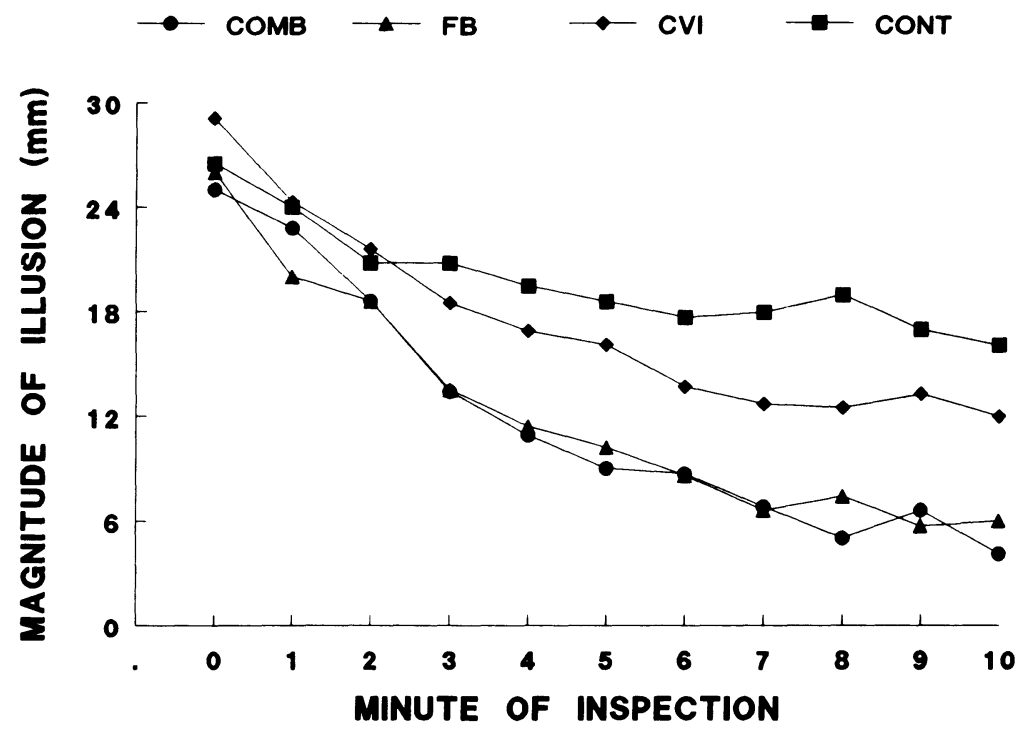

Figure 1. Mean accuracy scores as a function of minute of inspection for the subjects in the control (squares), visual-inspection (diamonds), feedback (triangles), and combined-procedures (circles) groups.

made adjustments in the absence of feedback and without visual inspection.

\begin{abstract}
Statistical Analysis
Mean accuracy scores were calculated by averaging magnitude of illusion across the 11 adjustments. An analysis of variance (ANOVA) for repeated measures, with Scheffé comparisons examining mean accuracy scores as a function of minute of inspection, was calculated for each group. Increases in accuracy between the first and final adjustments estimated the correction of inaccurate strategic factors, with structural factors estimated by residual error. Between-group differences were examined using ANOVAs and Scheffé comparisons.
\end{abstract}

\section{RESULTS}

There were no significant differences in mean accuracy scores as a function of sex (all $t$ tests $<1$, all $p s>.05$ ).

Mean accuracy scores for each group are presented in Figure 1 as a function of minute of inspection. There were no between-group differences in mean accuracy scores through Minute 2 [all $F \mathrm{~s}(3,76)<2.15$, all $p \mathrm{~s}>.05$ ], and from Minutes 3 through 10, the subjects in the feedback and combined-procedures groups were more accurate than those in the visual-inspection and control groups [all $F_{\mathrm{s}}(3,76)>10.15$, all $p \mathrm{~s}<.05$ ]. For Minutes 4 through 8 and Minute 10 , the visual-inspectiongroup subjects were more accurate than controls. The accuracy of subjects in each group significantly increased across all 11 adjustments [all $F \mathrm{~s}(10,190)>16.66$, all $p s<.05]$, and the following estimates of the relative contributions of strategic factors to illusion formation were observed: controls (39\%), visual inspection (50\%), feedback $(77 \%)$, and combined procedures $(84 \%)$.

\section{DISCUSSION}

Procedure-specific differences in illusion decrement were observed, estimates of strategic factors did not differ between the combined- procedures and feedback groups, and these estimates were higher than those for the visual-inspection and control groups. Training with visual inspection resulted in more illusion decrement than that observed for controls and, as found for the HV illusion, less than that for the subjects trained with feedback (Brosvic et al., 1991; Rowe-Boyer \& Brosvic, 1990). Thus, the use of visual inspection, relative to that of feedback, may lead to underestimation of the relative contributions of strategic factors in illusion formation.

The performance of the subjects trained with combined procedures and feedback in this study is similar to that observed using comparable procedures for the $\mathrm{HV}$ illusion, suggesting similar strategic etiologies for both illusions. However, direct numerical comparison is precluded by noteworthy differences in the production- and adjustment-task stimuli used to represent the HV illusion. The enhanced performance of the subjects trained with feedback in these studies presumably reflects assimilation of information on perceptual error into judgmental and problem-solving processes, although illusion decrement was observed for the subjects trained with visual inspection or control procedures. However, the mechanisms facilitating such correction for the latter groups have not been identified.

Studies are currently in progress examining the contributions of motor learning to performance on the ML and HV illusions.

\section{REFERENCES}

Brosvic, G. M., \& Cohen, B. D. (1988). The horizontal-vertical illusion and knowledge of results. Perceptual \& Motor Skills, 67, 463-469.

Brosvic, G. M., Rowe-Boyer, M. M., \& Dihoff, R. E. (1991). Acquisition and retention of perceptual learning and the horizontalvertical illusion. Perceptual \& Motor Skills, 72, 587-592.

Coren, S., Girgus, J. S., Erlichman, H., \& Hakstian, A. R. (1976). An empirical taxonomy of visual illusions. Perception \& Psychophysics, 20, 129-137.

Girgus, J. S., Coren, S., Durant, M., \& Porac, C. (1975). The assessment of components involved in illusion formation using a longterm decrement procedure. Perception \& Psychophysics, 18, 144-148.

Rowe-Boyer, M. M., \& Brosvic, G. M. (1990). Procedure-specific estimates of structural and strategic factors in the horizontal-vertical illusion. Perceptual \& Motor Skills, 70, 571-576. 